\title{
Ações Judiciais no Âmbito do Sistema Único de Saúde do Brasil, Bases Legais E ImPlicações: um Estudo de Caso em um Tribunal da Região Sudeste
}

\author{
JUDICIARY ACTIONS IN THE SCOPE OF THE BRAZILIAN HEALTH \\ SYSTEM, LEGAL BASES AND IMPLICATIONS: A CASE STUDY IN A \\ COURT OF THE SOUTHEAST REGION
}

\author{
Onofre Ricardo de Almeida Marques (*) \\ Marilene Barros de Melo ${ }^{(* *)}$ \\ Alessandra Patrícia de Souza Santos ${ }^{(* * *)}$
}

\section{RESUMO}

O presente artigo se propôs a analisar e compreender, a partir do banco de dados Sistema de Pesquisa Direito Sanitário - SPDISA, a base legal e o discurso utilizado pelos desembargadores ao proferirem as decisões judiciais referentes às ações que reivindicam o direito à saúde no âmbito do Sistema Único de Saúde - SUS. O estudo adotou a perspectiva qualitativa e analisou os acórdãos proferidos pelo Tribunal de Justiça de Minas Gerais - TJMG no período de 2000 a 2007. A análise documental se deu pela técnica de análise de conteúdo e o perfil das informações foi consolidado a partir de percentual simples. Encontrou-se um total de 4.217 acórdãos. Desses 83,87\% foram deferidos por antecipação de tutela. Evidenciou-se que o art. 196 da Constituição Federal de 1988 é o mais utilizado para a sustentação da sentença, em um percentual de $78,98 \%$. Contudo, desse percentual, $87 \%$

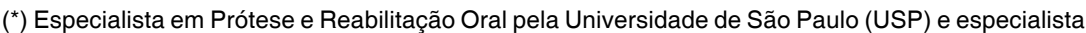
em Direito Sanitário pela Escola de Saúde Pública de Minas Gerais (ESP-MG), superintendente de Pesquisa da Escola de Saúde Pública do Estado de Minas Gerais. Belo Horizonte/MG-Brasil.

${ }^{\left({ }^{*}\right)}$ Especialista em Odontopediatria pela Universidade Federal de Minas Gerais (UFMG) e em Saúde Coletiva pela Pontifícia Universidade Católica de Minas Gerais (IEC/PUC Minas); mestre em Saúde Coletiva pela UFMG e doutora em Ciências da Saúde, na área de Planejamento, Gestão e Políticas pela Escola Nacional de Saúde Pública da Fundação Oswaldo Cruz - RJ. Belo Horizonte/MG-Brasil. $\left.{ }^{(* *}\right)$ Graduada em Psicologia pela Pontifícia Universidade Católica de Minas Gerais; trainee em pesquisa da Superintendência de Pesquisa da Escola de Saúde Pública do Estado de Minas Gerais. Belo Horizonte/MG-Brasil. Email: alessandrapatricia@yahoo.com.br. Recebido em 22.10.09. Aprovado em 17.06.10. 
das decisões utilizam apenas parte do artigo, argumentando que a Saúde é Direito de Todos e Dever do Estado, sem considerar as políticas públicas de saúde vigentes que buscam garantir a equidade no SUS.

\section{Palavras-chave:}

Direito Constitucional; Legislação Sanitária; Poder Judiciário; Poder Público; Serviços de Saúde.

\section{ABSTRACT}

This article intends to study, based on the database called Health Laws' Research System - SPDISA, the legal basis and the talking used by judges to utter sentences related to right to health in the scope of the Brazilian National Health System. This study has adopted a qualitative perspective by analyzing the sentences pronounced by the Court of Justice of Minas Gerais between 2000 and 2007. The documentary research was carried through the technique of content and the profile information was consolidated from simple percentages. A total of 4217 sentences were met and $83.87 \%$ of them were granted for guardianship anticipation. It became proved that the article 196 from the Brazilian Federal Constitution of 1988 has been used to sustain the sentence, in a percentage of $78,98 \%$. However, from this percentage, $87 \%$ of the decisions have used only part of the article, arguing that health is a right of all citizens and a duty of the state, without considering the effective public health politics which try to guarantee equity in SUS.

\section{Keywords:}

Constitutional Right; Health Services; Judiciary Power; Public Power; Sanitary Legislation

\section{INTRODUÇÃO}

A constituição da Organização Mundial da Saúde em 1946 foi o primeiro documento oficial a citar a saúde como um direito fundamental que não se refere à ausência de doença e sim às condições de "bem-estar físico, mental 
e social". Amplia, dessa forma, a concepção de saúde que reconhece a necessidade de compreender o homem em seu contexto social. Ao transformá-la na condição de direito, ela se situa como o centro das atenções e de estudo pelos sanitaristas e constituintes no Brasil, principalmente, durante a elaboração da Constituição da República Federativa - CF de 1988(1). Nesta, a saúde é concebida como "direito de todos e dever do estado" assegurado por políticas públicas que garantam o direito à vida e dignidade humana.

A saúde, como um bem e um direito social, é demarcada e estruturada em vários dos artigos constitucionais e associada às condições de vida como lazer, moradia, previdência social, proteção à maternidade e à infância, segurança, assistência aos desamparados.

Na perspectiva acima assinalada, em 1990, a Lei n. $8.080^{(2)}$ regulamenta o Sistema Único de Saúde - SUS e adota como seus princípios doutrinários a Universalidade, Integralidade e Equidade, e, como organizativos, a descentralização, regionalização e hierarquização. Propondo, ainda, uma série de atividades que vão desde a alocação de recursos, até a previsão de ações e serviços de saúde.

Esse contexto favorece o fortalecimento dos direitos sociais, mas, diante da amplitude geográfica brasileira e da sua diversidade cultural, econômica, social e epidemiológica, pode contribuir para que diferentes demandas e necessidades relativas às ações e serviços de saúde possam ser ainda mais dificilmente atendidas. Perante o acesso limitado às ações e serviços de saúde, alguns usuários tentam alcançá-los por meio de ações judiciais. Este fenômeno é conhecido como judicialização da saúde e tem ocorrido com grande frequência, nos últimos anos, em diversos tribunais. Conforme Vallinder(3), a judicialização da política se caracteriza pela difusão da arena decisória judicial e/ou na adoção de mecanismos judiciais em arenas de deliberação política. $\mathrm{O}$ conceito dado pelo autor propõe que o julgamento de ações que envolvam políticas governamentais constitui, por si só, um processo judicialização da política. Somado a isso, a utilização de procedimentos jurídicos na ordenação do mundo político também constitui este processo. No âmbito da saúde, as ações judiciais são geralmente direcionadas para obter medicamentos ou internação na rede hospitalar. Os pleitos podem ser direcionados a qualquer uma das três esferas do SUS - Municípios, Estados, Distrito Federal e União, tendo em vista a co-dependência como um de princípios organizativos desse sistema.

(1) BRASIL. Presidência da República. Constituição da República Federativa do Brasil. Brasília: Senado Federal, 1988. Disponível em: <http://www.planalto.gov.br/ccivil_03/Constituicao.htm>. Acesso em: 15 dez. 2008.

(2) BRASIL. Ministério da Saúde. Lei n. 8.080, de 19 de setembro de 1990. Dispõe sobre as condições para promoção, proteção e recuperação da saúde, a organização e funcionamento dos serviços correspondentes e dá outras providências. Diário Oficial da União, Brasília, 20 set. 1990. (3) VALLINDER, Torbjorn. When the Courts Go Marching In. In: VALLINDER, Torbjorn; TATE, Neal. The global expansion of judicial power: the judicialization of politics. New York: New York University Press, 1995. 
Diante da elevação das demandas, a Secretaria de Estado da Saúde de Minas Gerais - SES-MG em parceria com a Escola de Saúde Pública do Estado de Minas Gerais - ESP-MG e o Ministério Público decidiram compilar as ações judiciais relacionadas ao SUS no período de 2000 até 2007. Reuniu-se, então os julgamentos proferidos pelos Tribunais, conforme art. 163 do Código de Processo Civil Brasileiro, publicados na página dos seguintes tribunais: Tribunal de Justiça de Minas Gerais - TJMG, Tribunal de Justiça do Rio Grande do Sul - TJRS, Tribunal de Justiça do Rio de Janeiro - TJRJ, Superior Tribunal de Justiça - STJ e Supremo Tribunal Federal - STF. A consolidação dos dados resultou em um software específico — SPDISA construído pelo grupo de estudo de Direito Sanitário da ESP-MG.

Neste sentido, o presente artigo resulta de um trabalho de conclusão do curso de especialização em Direito Sanitário da ESP-MG. Tem como objetivo analisar e compreender a partir do banco de dados SPDISA a base legal e o discurso utilizado pelos juízes e desembargadores do TJMG ao proferirem as decisões judiciais referentes às ações que reivindicam o direito à saúde no âmbito do Sistema Único de Saúde - SUS. Acredita-se que esta análise beneficie o campo de conhecimento em relação às ações judiciais em saúde, facilitando uma maior integração entre o campo da saúde, o poder judiciário e a sociedade como um todo.

\section{O PROCESSO DE CONSTRUÇÃO DO SUS}

Do início do século até o final dos anos 70, as ações e serviços de saúde prestadas no âmbito público no Brasil eram privilégios de alguns grupos de trabalhadores da região urbana, vinculados formalmente ao mundo do trabalho, mediante contribuições mensais compulsórias atreladas à previdência social. O restante da população, para ter acesso ao serviço de saúde, recorria ao setor privado, Santas Casas de Misericórdia ou aos postos de saúde municipais. Assim, o sistema de saúde era caracterizado como excludente, socialmente desigual e com escassez de recursos. Nesse mesmo período, evidenciava-se um acelerado desenvolvimento tecnológico e da microbiologia que induziu o surgimento de novas especialidades e o crescimento das indústrias de medicamentos e equipamentos, reproduzindo um modelo hospitalocêntrico, de alta tecnologia e acentuada medicalização.

No final dos anos 70 e início dos anos 80, associava-se a essa situação, uma grave crise econômica que afetava acentuadamente a qualidade de vida da população. Diante desse cenário, alguns setores da sociedade se organizaram em uma frente para a redemocratização do país, exigindo mudanças no sistema de saúde, fortalecendo o movimento da reforma sanitária no Brasil que buscou romper com o modelo acima apresentado e se constituiu como a possibilidade de compreender a saúde como um 
processo permeado por outros determinantes além do biológico, como os culturais, econômicos, históricos e sociais, além de avançar em direção a um sistema de saúde baseado em ações integrais de saúde e na saúde como um direito universal.

Em 1986, a VIII Conferência Nacional de Saúde consagrou e sistematizou o corpo doutrinário das bases da Reforma Sanitária Brasileira a ser proposto na Assembleia Nacional Constituinte em 1987. A nova Constituição brasileira - CF de 1988 - incorporou parte desse corpo que, posteriormente, deu base ao Sistema Único de Saúde - SUS. Em 1990, as Leis Federais n. 8.080, nomeada de lei orgânica da saúde, e n. 8.142(4), regulamentaram o SUS.

Esse sistema tem abrangência nacional e se tornou responsável pelo conjunto de todas as ações e serviços de saúde prestados no âmbito público, com o componente federal, um em cada estado e em cada município, enquanto a iniciativa privada participou de maneira complementar. O SUS é considerado como uma das maiores conquistas sociais da CF de 1988, uma vez que democratizou as ações e serviços de saúde, ao demarcá-los como universais e descentralizados, favorecendo o acesso e com ênfase nos municípios, além de adotar uma concepção ampliada de saúde a qual é associada no nível de organização econômica e social brasileira e a um conjunto de bens: educação, trabalho, alimentação, moradia, nível de renda, meio ambiente, saneamento básico, vigilância sanitária e farmacológica, lazer etc.

No que concerne às estruturas que ajudam a consolidar o SUS e assim torná-lo um instrumento do direito à saúde, evidencia-se a participação popular, como condição essencial e como um ato de desenvolvimento de cidadania. A obrigatoriedade da estruturação de conselhos de saúde nas três esferas de governo se constituiu como a necessidade de inclusão do usuário nos processos decisórios, tanto na fase de formulação quanto na de implementação, configurando legitimidade a essas decisões, já que, o direito à saúde é demarcado pela participação social e o ator social com maior credibilidade para isso é a comunidade local pelas suas vivências e necessidades. Assim, esse direito, apesar de ser instituído por lei, somente adquire propriedade quando a comunidade se torna corresponsável pela garantia dos princípios norteadores do sistema.

Diante deste cenário, Paim ${ }^{(5)}$, ressalta que, o SUS vem se desenvolvendo ao longo dos anos e pode ser caracterizado em quatro vertentes. A primeira

(4) BRASIL. Ministério da Saúde. Lei n. 8142, de 28 de dezembro de 1990. Dispõe sobre a participação da comunidade na gestão do Sistema Único de Saúde - SUS e sobre as transferências intergovernamentais de recursos financeiros na área da saúde e dá outras providências. Diário Oficial da União, Brasília, 28 dez. 1990. Disponível em: <http://www81.dataprev.gov.br/sislex/ paginas/42/1990/8142.htm>. Acesso em: 18 dez. 2008.

(5) PAIM, Jairnilson Silva. Políticas de saúde no Brasil. In: ROUQUAYROL, Maria Zélia; ALMEIDA FILHO, Naomar; TAMBELLINI, Anamaria Testa (Orgs.) et al. Epidemiologia \& Saúde. 6. ed. Rio de Janeiro: Medsi, 2003. p. 587-603. 
relaciona-se ao SUS formal, assegurado pelo seu aparato jurídico e normativo. A segunda, o SUS democrático, sustentado pelo seu corpo doutrinário. A terceira representa o SUS real, resultante das questões econômicas e particularistas próprias do Estado brasileiro; e o SUS para pobres, sustentado por políticas focalizadas. Na visão de Elias $^{(6)}$, a realidade do SUS é demarcada por dificuldades permanentes como a carência de recursos financeiros para atender à totalidade das demandas, além de outros problemas relacionados ao repasse desses recursos; à fragilidade dos seus princípios organizativos, principalmente, no que se refere à regionalização e hierarquização, à ausência de parâmetros claros para salários e cargos, bem como, posicionamentos divergentes dos profissionais e gestores quanto ao sistema.

\section{MATERIAL E MÉTODO}

Este estudo é de perspectiva qualitativa e de caráter transversal. Procedeu-se a uma análise dos acórdãos proferidos pelo Tribunal de Justiça de Minas Gerais - TJMG no período de 2000 a 2007 com um total de 4.217 compilados no software SPDISA. Caracterizou-se como uma análise documental que teve o propósito de atingir um armazenamento condensado de informações significativas das decisões judiciais, em seus aspectos qualitativos. Essa análise se constituiu a partir da técnica de análise de conteúdo com base em Bardin ${ }^{(7)}$ e proporcionou uma visão mais organizada e imparcial quanto ao registro das decisões, inserindoas no contexto em que foram produzidas.

Determinou-se como categorias de análise, três existentes no SPDISA: 1 - resultados das decisões judiciais; 2 - base legal utilizada; 3 - discursos utilizados pelos desembargadores. Desta última, extraiu-se cinco subcategorias: 1 - a saúde é direito de todos e dever do Estado; 2 - A saúde é direito de todos e dever do Estado mediante a existência de políticas públicas; 3 entraves burocráticos não podem obstar a viabilidade de um direito; 4 - as políticas públicas são as sustentações ao direito a saúde; e 5 - mais de um fundamento.

O perfil das informações foi consolidado mediante frequência simples.

\section{RESULTADOS E DISCUSSÃO}

O aumento de cerca de $80 \%$ no número de ações judiciais referentes às ações e serviços do SUS, a partir do ano de 2003, tem demandado estudos

(6) ELIAS, Paulo Eduardo. Estado e saúde: os desafios do Brasil contemporâneo. Revista São Paulo Perspectiva, São Paulo, v. 18, n. 3, p. 41-46, 2004.

(7) BARDIN, Laurence. Análise de conteúdo. Lisboa: Edições 70, 1977. 287 p. 
no sentido de conhecer a razão desse crescimento. Principalmente, em 2007, quando, houve uma alta expressiva. A partir da amostra do período de 2000 a 2007 , verifica-se que $83,87 \%$ delas foram deferidas, conforme Tabela 1 , por meio de liminares como a Antecipação de Tutela.

\section{TABELA 1}

Resultados das Decisões Judiciais presentes no sítio do Tribunal de Justiça de Minas Gerais - TJMG - referentes às ações de saúde ofertadas pelo SUS, em valores absolutos e percentuais no período de 2000 a 2007

\begin{tabular}{|l|c|c|}
\hline \multicolumn{1}{|c|}{ Resultados das Ações } & Número Absoluto & Percentual \% \\
\hline Deferidas quanto à Antecipação de Tutela & 3537 & 83,87 \\
\hline Indeferidas quanto à Antecipação de Tutela & 680 & 16,13 \\
\hline TOTAL & 4217 & 100,00 \\
\hline
\end{tabular}

Fonte: Tabulação Tribunal de Justiça de Minas Gerais no período de 2000 a 2007.

A opção dos juízes pela antecipação de tutela tem sido amplamente utilizada em razão da facilidade da produção de provas clara e precisa na área de saúde, e, dessa forma, garantir o adiantamento do atendimento ao pedido antes do julgamento do mérito. $\mathrm{O}$ alto percentual desse tipo de liminar tem viabilizado questionamentos e a necessidade de se entender como ela tem sido concedida, uma vez que, geralmente, não há reversão da medida antecipada. Situação que pode estar associada a outros critérios além dos utilizados para a antecipação, tais como: a saúde é um direito positivado sendo, muitas vezes, satisfeito pela natureza do problema, ou seja, não tem como reverter uma ação que já foi satisfeita, mesmo perante a não satisfação imediata do pedido. Geralmente, pedidos como internação, prótese, exames, entre outros, são satisfeitos imediatamente com tutela antecipada sem a possibilidade de reversão da medida. Esta pode ocorrer no caso de fornecimento de medicamento em longo prazo, pela sua interrupção.

Os magistrados ao concederem a antecipação de tutela argumentam que não podem se submeter ao perigo da demora processual relacionada ao trâmite legal, o que pode gerar o agravamento da doença ou ameaçar o alienável direito à vida. Nesta perspectiva, o Estado deve garantir os meios necessários para disponibilizar o solicitado pelo autor de maneira a não comprometer a sua subsistência.

Reconhece-se que os critérios adotados pelo Judiciário seriam reflexos de diversas variáveis e resultam em várias implicações para o SUS. Assim, faz-se necessária uma correlação da antecipação de tutela com a legislação utilizada para subsidiar a decisão do judiciário. Inicialmente, buscou-se conhecer qual a legislação subsidia a decisão judicial: de natureza 
Constitucional, Infraconstitucional, Políticas Públicas, ou Não Definidas. De acordo com a Tabela 2, a mais utilizada era a de base constitucional.

TABELA 2

Legislações utilizadas para subsidiar os Acórdãos no sítio do Tribunal de Justiça de Minas Gerais, no período de 2000 a 2007 relativos às ações e serviços de saúde no âmbito do SUS, em valores absolutos e percentuais

\begin{tabular}{|c|c|c|}
\hline Legislação & Número Absoluto & Percentual \% \\
\hline Constituição & 3507 & 83.16 \\
\hline Infraconstitucional & 618 & 14.67 \\
\hline Políticas Públicas & 61 & 1.44 \\
\hline Não consta & 31 & 0.73 \\
\hline Total & 4217 & 100,00 \\
\hline
\end{tabular}

Fonte: Tabulação do Tribunal de Justiça de Minas Gerais no período de 2000 a 2007.

Como se pode observar, na Tabela 2, é com base nos preceitos constitucionais, que o Judiciário tem respaldado $83,16 \%$ dos seus pareceres. Dentre a legislação Constitucional, os artigos mais empregados são: 1ํㅜ $3^{\circ}$, $5^{\circ}, 6^{\circ}$ e 196. Além de outros referentes à saúde onde o direito à saúde estava acima de qualquer argumento, mesmo diante da inexistência de recursos públicos ou da indisponibilidade financeira, uma vez que não há direito que sobreponha a vida e a saúde.

A legislação de base infraconstitucional tem norteado $14,67 \%$ das decisões judiciais que se sustentam em leis ou instrumentos não integrantes na CF de 1988. Estas decisões estão hierarquicamente abaixo da Constituição; diz-se de norma jurídica que abrange todo o ordenamento "inferior" positivo do Estado, indo das leis federais, estaduais e municipais aos expedientes ordinativos de feição mais burocrática. A Lei mais utilizada é a 8.080, considerada a Lei Orgânica da Saúde, pois regulamenta o SUS.

As decisões judiciais subsidiadas pelas Políticas Públicas girou em torno de $1,44 \%$. De acordo com Bucci(8), elas têm suporte em programas públicos que coordenam as ações disponíveis ao estado e ao âmbito privado, baseadas no direito público com objetivos voltados para as necessidades do coletivo, e, a partir do princípio ético, evitam privilegiar os interesses individuais ou de grupos específicos e se centram na responsabilização quanto ao mundo social. No âmbito do TJMG, advêm de Atos Normativos da administração pública, como a Portaria n. 2.577 de medicamentos excepcionais, a mais utilizada; a portaria que dá sustentação à cirurgia bariátrica, entre outras.

(8) BUCCI, Maria Paula. Dallari. Cidadania, direitos humanos e políticas públicas: perspectivas de justiça no Século XXI. Cadernos de Direito e Cidadania III, São Paulo, 2002. 
O quesito "não consta" se refere às decisões nas quais não foi possível estabelecer qual a legislação utilizada.

\section{A análise de conteúdo dos discursos}

O tipo de discurso utilizado nas decisões judiciais pertinentes às ações e serviços no âmbito do SUS é consolidado na Tabela 3. Observa-se uma tendência do Judiciário em seguir o art. 196, no que diz respeito ao direito absoluto à saúde, com um total de 3.331 no período de 2000 a 2007. Destes $71,33 \%$ reproduziam apenas parte do art. 196 para sustentar o direito do cidadão à saúde, sem associar esse direito às políticas públicas voltadas ao campo da saúde, pois entende a saúde como direito inerente ao ser humano e dever do Estado, se situando como um dos direitos fundamentais que tem por objetivo garantir aos cidadãos condições sociais e materiais de existência. Por isso, deve ser garantido de forma integral e igualitária, independente de legislação infraconstitucional ou quaisquer outras medidas impeditivas. Este artigo também serviu de base na maioria dos casos de tutela antecipada.

TABELA 3

Tipo de fundamentação utilizada nas decisões judiciais pertinentes às ações e serviços no âmbito do SUS, presentes no sítio do Tribunal de Justiça de Minas Gerais no período de 2000 a 2007, em valores absolutos e percentuais

\begin{tabular}{|l|c|c|}
\hline \multicolumn{1}{|c|}{$\begin{array}{c}\text { Discursos } \\
\text { A saúde é direito de todos e dever do Estado }\end{array}$} & Acórdãos & Percentual \% \\
\cline { 2 - 3 } & 3008 & 71,33 \\
\hline $\begin{array}{l}\text { A saúde é direito de todos e dever do Estado } \\
\text { mediante a existência de políticas públicas }\end{array}$ & 323 & 7,65 \\
\hline $\begin{array}{l}\text { Entraves burocráticos não podem obstar a } \\
\text { viabilidade de um direito }\end{array}$ & 760 & 18,02 \\
\hline $\begin{array}{l}\text { As políticas públicas são as sustentações } \\
\text { ao direito à saúde }\end{array}$ & 25 & 0,52 \\
\hline Mais de um fundamento & 101 & 2,48 \\
\hline Total & 4217 & 100,00 \\
\hline
\end{tabular}

Fonte: Tabulação do Tribunal de Justiça de Minas Gerais no período de 2000 a 2007.

Como assinalado acima, o Judiciário mineiro tem fundamentado as suas decisões na essencialidade de manutenção da saúde, argumentando em $18,02 \%$ das decisões que esse direito não pode ficar subordinado a entraves burocráticos. É o segundo discurso mais utilizado. Entre esses entraves se encontram os administrativos, financeiros, protocolo clínico, entre outros, 
os quais segundo alguns juízes e desembargadores não podem obstar a viabilidade de um direito. Enfatizam que as portarias elaboradas pelo Ministério da Saúde devem obedecer às Constituições Federal e Estadual e outras leis, e apontam a inaplicabilidade da Teoria da Reserva do Possível quando se trata da preservação de direito à vida e à saúde. Essa teoria pressupõe que não se pode impor ao ente público o atendimento às situações que fogem ao âmbito do possível ou do viável. Realçam que diante da ameaça ao direito à saúde e à vida, a prerrogativa jurídica representa o poder do cidadão de exigir, de qualquer dos entes federativos, o atendimento das suas necessidades em saúde, garantindo o princípio da dignidade humana, uma vez que a improcedência da ação põe em risco o direito à saúde e à integridade física do cidadão, direitos maiores que se sobrepõem a qualquer outro.

Em relação ao discurso que se ampara no art. 196 da CF de 1988 de maneira integral: "a saúde é um direito de todos e um dever do Estado garantido mediante políticas sociais e econômicas que visem à redução do risco de doença e outros agravos, além de proporcionar o acesso universal e igualitário às ações e aos serviços para sua promoção, proteção e recuperação", é o terceiro discurso mais utilizado, gira em torno de $7,65 \%$. No entanto, observa-se um crescimento acentuado desse discurso se comparado com os que se sustentam apenas na primeira parte do art. 196. A partir desse artigo, algumas decisões judiciais consideram que o direito à saúde deve ser condicionado às políticas públicas. Estas são instrumentos de regulação estatal, baseadas na relação Estado, economia e sociedade, capazes de atender às necessidades de determinado grupo ou o coletivo e de minimizar as desigualdades econômica e social e/ou conflitos de interesses. Têm, assim, a incumbência de organizar e administrar a coisa pública, visando favorecer os preceitos da cidadania e do bem público. Pensar nesses preceitos nos remete à condição de que a construção de uma política pública busca se aproximar e se apropriar das necessidades inerentes a um determinado grupo social e não privilegiar alguns poucos.

$\mathrm{Na}$ visão de $A r e n d t^{(9)}$, cabe à política compreender a pluralidade dos indivíduos e inserir todos no processo de construção da sociedade. Afirma que "o sentido da política é a liberdade", baseia-se no princípio da pluralidade e da equidade, norteando-se nos diferentes e "não dos iguais". A autora acrescenta que o sujeito depende dos outros para a sua existência, assim o provimento para a vida depende de todos. Nesta perspectiva, apesar da liberdade do sujeito buscar garantir seu acesso às ações e serviços de saúde, ele deve analisar que solicitar judicialmente um determinado fármaco, em fase experimental, sem eficácia comprovada não pode ser considerado essencial e estará de alguma maneira fragilizando a vida de outros sujeitos

(9) ARENDT, Hannah. O que é política? Trad. Reinaldo Guarany. 6. ed. Rio de Janeiro: Bertrand Brasil, 2006. 
no seu sentido mais amplo, uma vez que em uma coletividade tem-se a capacidade de influenciar o que acontece em volta de todos. Cada um tem a sua responsabilidade quanto à consolidação da justiça social, da democracia e do direito à vida. Para isso, é fundamental mais compartilhamento, solidariedade e responsabilidade quanto ao uso racional, pois a política envolve um todo, a polis.

No âmbito do SUS, esse todo é enfatizado por um dos seus princípios doutrinários, a universalidade que garante o processo de atenção à saúde a todos os cidadãos brasileiros, enquanto que o segundo princípio, da equidade, busca abranger a pluralidade econômica e social vigente no país, trabalhando desigualmente os desiguais. E, o terceiro princípio, a integralidade assegura o atendimento a todos os tipos de necessidades em saúde, ações preventivas, consultas, exames, medicamentos, equipamentos de suporte à vida, cirurgia, entre outros.

Atender a esses três princípios é uma condição que tem escapado do âmbito do executivo, por não conseguir abranger a totalidade proposta pela política pública. Essa lacuna tem sido preenchida pelo Judiciário que procura assegurar as ações e serviços de saúde no âmbito do individual. Situação que pode estar privilegiando um usuário em detrimento do coletivo. Entretanto, diante de alguns episódios de desvios de dinheiro, a alegação quanto à insuficiência de recursos parece frágil diante do contexto de um sujeito doente e de possíveis sequelas irreversíveis.

A supremacia da base constitucional fica evidente quando se verifica que os discursos baseados em políticas públicas referentes à saúde se concentram em apenas $0,52 \%$ das decisões, que, na sua maioria, situam as políticas públicas como um limite para viabilizar o acesso a um direito garantido pela Constituição da República de 1988. Ressaltam, ainda, que no momento de formulação e implementação das políticas sociais e econômicas deve-se constituí-las de maneira idônea e não como uma simples extensão dos preceitos constitucionais, visto que eles devem ser integralmente respeitados e plenamente garantidos. Caso contrário, estarão simplesmente adotando um grave comportamento anticonstitucional.

Em 12 de maio de 2010, o Senado aprovou um novo capítulo na Lei Orgânica de Saúde que exige do poder público a disponibilização de medicamentos e produtos de saúde aos usuários, mesmos os não constantes nas tabelas do SUS. E, havendo atraso na atualização das tabelas e protocolos clínicos, que deverá ser anual, o fornecimento acontecerá mesmo sem prescrição e/ou laudo médico. Essa posição do legislativo é uma maneira de responsabilizar o Estado no cumprimento de seus deveres e favorece a regulação do sistema de gestão da saúde.

Encontram-se, além disso, 101 acórdãos que tiveram sua fundamentação constituída por mais de um dos critérios. 
A análise de conteúdo dos discursos relativos às decisões que indeferiam a solicitação do usuário demonstrou que na visão da maioria desses magistrados e desembargadores dever-se-ia respeitar a interdependência dos três poderes de organização do Estado brasileiro. Salientava que não cabia ao Judiciário determinar a efetivação de políticas públicas, muito menos intervir em questão de competência exclusiva do Poder Executivo. Outros pautaram suas decisões na certeza de que o Estado deve conceder tratamento adequado e eficaz, baseado nos protocolos clínicos estruturados no âmbito da assistência e em medicamentos constantes em suas listas. Dessa forma, ele estará evitando "qualquer tratamento" e promovendo mais dignidade e menor sofrimento aos seus cidadãos. A não ser que o usuário comprove a ineficácia do produto concedido, pelo protocolo ou pela lista. Entretanto, o judiciário alerta que não se observa na demanda essa comprovação e sim um movimento ao contrário do usuário, isto é, buscar sempre valorizar o que não é ofertado pelo SUS. Diante desse fato, enfatizavam que não se pode confundir o dever do Estado com direito de escolha do usuário e/ou de seu médico. Ressaltavam, ainda, que a padronização é um instrumento eficiente para uma gestão de qualidade, ela busca sustentação em condições de melhor desempenho, maior impacto nas condições de saúde do usuário e menor custo. Sendo assim, deve-se aplicar a teoria da reserva do possível quando o Estado pode oferecer um produto de menor custo e de igual valia quando confrontado com o de maior custo, indo ao encontro do possível ou do viável.

\section{Os princípios doutrinários que regem o SUS versus a concepção desses para o Poder Judiciário Mineiro}

Compreendendo os princípios doutrinários do SUS como fundamentais para dar sustentabilidade e estabilidade ao Direito à Saúde, cabe, a partir desse estudo, discuti-los à luz dos seus significados no âmbito desse sistema, bem como, a partir das decisões judiciais do TJMG, principalmente, quando se reconhece que a base desses se constituiu no art. 196 da CF de 1988, que tem fundamentado as decisões judiciais.

De acordo com a CF de 1988, o princípio da universalidade busca garantir a oferta de ações e serviços de saúde a todos os cidadãos brasileiros que necessitem, pois, de acordo com o art. 5으 da CF/88, todos são "iguais perante a lei". No art. 6으, a saúde é demarcada como direito social. Dentro dessa concepção, o art. 196 afirma que a "Saúde é direito de todos e dever do Estado", garantido pela execução de políticas econômicas e sociais e pela garantia do acesso universal igualitário às ações e serviços de saúde. Assim, o poder público tem a obrigação de assegurar as condições indispensáveis ao pleno exercício, objetivando condições adequadas de saúde, a partir da ênfase em ações preventivas e na redução dos agravos. Nessa perspectiva, 
a Lei n. 8.080 que regulamenta o SUS, denominada de Lei Orgânica da Saúde, institui a necessidade do SUS obedecer ao princípio da "universalidade de acesso aos serviços de saúde em todos os níveis de assistência".

Diante dessas concepções, evidencia-se certa superposição nos princípios da universalidade, equidade e integralidade, visto que a Constituição associa a universalidade à cobertura de todos os cidadãos brasileiros natos ou naturalizados ao SUS, independente da etnia; local de residência, faixa etária, condição social, econômica ou cultural, e, ao princípio da igualdade, ao estabelecer que o acesso desses cidadãos deve ser igualitário. Estaria, portanto, inviabilizando a particularização dos beneficiários. Acrescenta-se a essas acepções, a compreensão da Lei n. 8.080 que vincula a universalidade à qualificação do conteúdo da assistência prestada.

$\mathrm{Na}$ análise das decisões judiciais, observou-se em todas que os discursos do poder judiciário tinham posicionamentos semelhantes ao da CF/88 e da lei orgânica da saúde. Salientavam que o processo de atenção à saúde prestado pelo SUS deve abranger a totalidade da população brasileira sem nenhum tipo de exceção. Em algumas decisões, verificou-se, como já assinalado, uma ênfase à qualidade das ações e serviços prestados, conforme preconiza a Lei n. 8.080

Quanto ao acesso universal igualitário, verifica-se uma relação entre a CF/88 e o art. $7^{\circ}$ da Lei n. 8.080, que os conceituam como a "igualdade da assistência à saúde, sem preconceitos ou privilégios de qualquer espécie". Concepção na qual o judiciário mineiro tem se sustentado para julgar as ações. No entanto, pode-se perceber, que diante da desigualdade social existente no Brasil, a Constituição em seu art. 196 procura assegurar a equidade no processo de atenção à saúde do SUS, ao vincular o direito à saúde às políticas econômicas e sociais voltadas para a redução de riscos e agravos à saúde, bem como, quando em seu art. 198 e a Lei n. 8080 estabelecem entre os princípios organizativos do SUS, a regionalização e a descentralização, que, segundo Lucchese $^{(10)}$, favorecem a proximidade com os problemas advindos da realidade local e o equilíbrio de oportunidades entre seus diversos sujeitos com a construção de respostas mais específicas ao sujeito ou a determinado grupo de sujeitos de maneira a alcançarem seu potencial de saúde. A autora afirma que a equidade pode ser assegurada a partir da distributividade e seletividade baseadas em indicadores epidemiológicos e de efetividade das ações e serviços prestados. Para isso, é importante que a gestão pública procure mediar as necessidades/demandas sociais com a administração dos recursos governamentais disponíveis. Esse é o grande desafio do poder público diante da diversidade e da complexidade que

(10) LUCCHESE, Patrícia Tavares Ribeiro. Equidade na gestão descentralizada do SUS: desafios para a redução de desigualdades em saúde. Ciência \& Saúde Coletiva, Rio de Janeiro, v. 8, n. 2, p. 439-448, 2003. 
envolve as questões sociais brasileiras; assim, convive-se com lacunas que o Judiciário mineiro tem sido obrigado a compensar.

A Organização Pan-americana de Saúde - OPS(11) alerta que a articulação das demandas sociais, necessidades/recursos é uma das maneiras de garantir a equidade, uma vez que possibilita a minimização das diferenças evitáveis e injustas ao mínimo possível Soares ${ }^{(12)}$ sinaliza que a equidade possui dois enfoques: o econômico e o da justiça. $\mathrm{O}$ seu enfoque econômico é caracterizado como a distribuição eficiente de recursos, destinando políticas de focalização e recursos aos mais necessitados. Enquanto que, o enfoque no referencial da justiça, é diferente ao da igualdade, pois viabiliza a "correção da situação de igualdade", assumindo a posição de um princípio de justiça social, o qual o Judiciário mineiro adota como se fosse a perspectiva da igualdade.

Uma das estratégias necessárias para que o campo da saúde se adeque à equidade, segundo Almeida $^{(13)}$, é de se distinguir a necessidade de saúde do sujeito da necessidade do sujeito quanto aos serviços de saúde. A primeira se relaciona às desigualdades nas condições de vida e saúde e a segunda, às desigualdades no acesso e consumo de serviços de saúde, na medida em que essa distinção pode priorizar a destinação dos serviços públicos aos de menor poder aquisitivo, além de orientar as decisões judiciais.

Em relação ao princípio da integralidade, o art. 196 da CF/88 determina como o acesso às ações e serviços para sua "promoção, proteção e recuperação". É definido nessa CF, em seu art. 198, como "atendimento integral, com prioridade para as atividades preventivas, sem prejuízo dos serviços assistenciais". E, na Lei n. 8.080, em seu art. 7º, como o "conjunto articulado e contínuo das ações e serviços preventivos e curativos, individuais e coletivos, exigidos para cada caso em todos os níveis de complexidade do sistema", a partir de preceitos éticos e científicos. Busca, então, efetivar todos os cuidados demandados pelo sujeito, em todos os aspectos preventivos e assistenciais, durante todo o tempo de sua vida.

Entretanto, percebe-se nas decisões judiciais mineiras uma fragilidade em relação ao que seja integralidade articulada, em algumas situações, à noção de consumo, reduzida às ações paliativas, aproximando do que Vieira $^{(14)}$ assinala como a ausência de reconhecimento de que é um princípio

(11) OPS — ORGANIZACIÓN PANAMERICANA DE LA SALUD. La cooperación de la Organización Panamericana de la Salud ante los procesos de reforma del sector salud. Washington, 1997. $31 \mathrm{p}$. (12) SOARES, Orlando. Comentários à Constituição da República Federativa do Brasil: (promulgada em 05.10.1988). 10. ed. Rio de Janeiro: Forense, 1999. 903 p.

(13) ALMEIDA, Célia Maria. Reforma de sistemas de servicios de salud y equidad en América Latina y el Caribe: algunas lecciones de los años 80 y 90. Caderno de Saúde Pública, Rio de Janeiro, v. 18, n. 4, p. 905-925, 2002.

(14) VIEIRA, Fabíola Sulpino. Ações judiciais e direito à saúde: reflexão sobre a observância aos princípios do SUS. Revista de Saúde Pública, São Paulo, v. 42, p. 365-369, 2008. 
regido por uma política pública que busca garantir o caráter fundamental de promoção e prevenção de doença e agravos. Diante disso, fica clara a dificuldade de ação, do ponto de vista do entendimento das ações de saúde, já que um processo de atenção integral não tem como referência o acesso a um determinado recurso, porque ele é de última geração ou de maior preço. Critérios, algumas vezes, considerados padrão para o usuário e referendados pelo Judiciário.

Assim, cabe ao Judiciário buscar estratégias que certifiquem se a prescrição das ações e serviços em saúde tem base científica, uma vez que a integralidade presumida na reforma sanitária visava à garantia de direitos baseados na real necessidade em saúde e não induzidos por uma base forte no capital e certa fragilidade científica e ética. Segundo Carvalho(15), trata-se de uma integralidade regulada que busca assegurar um processo de atenção integral em saúde que vai da atenção básica à de alta complexidade, desde que dentro dos preceitos éticos e científicos.

Salienta-se a importância do respeito aos valores éticos e científicos nas decisões judiciais, mesmo quando essa se apoia em parâmetros constitucionais, especialmente, diante da extensão territorial brasileira e da complexidade social, econômica e histórica associados à finitude dos recursos financeiros e à inexistência de linearidade quando se trata da relação Estado/ sociedade/saúde.

Diante disso, cabe ao Poder Judiciário uma posição plenamente ativa na sociedade de maneira a se posicionar como um agente transformador que busque, nas suas decisões judiciais pertinentes ao SUS, contemplar tanto os princípios doutrinários quanto os organizativos do SUS. Não seria imprudente pensar que o sistema judiciário poderia desenvolver um departamento, área, ou mesmo uma vara especializada específica para tratar de assuntos referentes à saúde.

Com isto, haveria uma ação mais contundente em relação à judicialização da saúde na qual o sistema judiciário atuaria de uma forma mais consciente e não como resposta a situações que já foram preparadas de forma que o tribunal não tenha alternativa, uma vez que segue a Constituição como a base de sua posição. Em outras palavras, o Judiciário não ficaria refém de um sistema viciado e manipulado pelos poderes econômicos, políticos e até mesmo social ${ }^{(16)}$.

(15) CARVAlHO, José Murilo. Pontos e bordados. Belo Horizonte: Ed. UFMG, 1999. 457 p.

(16) MELO, Maurício de Medeiros $O$ direito coletivo prestacional à saúde e o poder judiciário: a concretização do art. 196 da Constituição de 1988 pela via jurisdicional. 2007. Dissertação (Mestrado) — Faculdade de Direito, Universidade Federal do Rio Grande do Norte, Natal. 2007. Disponível em:<http://bdtd.bczm.ufrn.br/tedesimplificado//tde_busca/arquivo.php?codArquivo=1162>. Acesso em: 03 dez. 2008. 


\section{Desafío para o Poder Judiciário: SUS Legal versus SUS Real}

$\mathrm{Na}$ análise das decisões judiciais observou-se que os preceitos legais em algumas situações não favorece a realidade do SUS, talvez diante da concepção de uma cidadania fragilizada marcada por necessidades e demandas em saúde, em algumas situações, não assistidas pela ineficiência de recursos. O que mais uma vez suscita o Poder Judiciário a conceder suas ações de acordo com as bases constitucionais. A Constituição Federal de 1988 é signatária de direitos e garantias fundamentais e traz, dentre os princípios e preceitos constitucionais, a dignidade da pessoa humana como um dos fundamentos da República. Este é um dos princípios constitucionais basilares do ordenamento jurídico brasileiro e todas as normas jurídicas são por ele atingidas. Em consonância com a ordem jurídica mundial, no que se refere à recepção de direitos e garantias fundamentais nas Constituições, a Carta brasileira estabelece os preceitos fundamentais inerentes ao ser humano e sua dignidade. Dentre eles, pode-se citar os direitos fundamentais de primeira geração, ou seja, os direitos denominados individuais, tais como vida, liberdade, direito de propriedade, dentre outros.

Cabe ressaltar que não há direito maior que outro, visto que não há hierarquia entre normas constitucionais; desta forma, todos são igualmente protegidos e garantidos. A força normativa da Constituição, marcada pelo movimento neoconstitucionalista que busca a constitucionalização do direito brasileiro e a interpretação do direito com base em princípios e não apenas na norma positiva, é realçada por Barroso(17). Defende, então, a aplicabilidade direta das normas constitucionais, independente das normas programáticas, dando origem ao que tem sido chamado de ativismo judiciário ou judicialização. Este procura garantir o chamado mínimo existencial. Situação evidenciada no âmbito das ações judiciais referentes ao SUS, que transforma as quatro vertentes - Formal, Real, Democrática e para Pobres - segundo Paim ${ }^{(18)}$, constituintes do SUS, em apenas duas - Formal e Democrática, viabilizadas pela decisão fundamentada, geralmente, na "saúde como direitos de todos e dever do Estado", sem levar em consideração as políticas que dão sustentação ao campo da saúde pública no Brasil e, pelo enfoque econômico e da justiça do princípio da equidade.

Contudo, o SUS Real e o SUS para Pobres se sobressaem o tempo todo, uma vez que o SUS Real, em seus vinte anos, tem apresentado várias conquistas, apesar dos diversos desafios enfrentados, e, o SUS para Pobres, tem outro enfoque, com taxas de utilização do SUS menores na região Nordeste e um crescimento menor de consultas médicas em regiões menos

(17) BARROSO, Luís Roberto. Da falta de efetividade a judicialização excessiva: direito à saúde, fornecimento gratuito de medicamentos e parâmetros para a atuação judicial. Revista Jurídica UNIJUS, Minas Gerais, v. 15, p. 13-38, 2008.

(18) PAIM, Jairnilson Silva. op. cit., p. 587-603. 
desenvolvidas, com exceção da região Centro-Oeste que ostenta um número de consultas maior que a região Sul. Encontra-se, uma diminuição do acesso aos serviços de saúde para os mais pobres e um percentual de busca de atendimento pelos usuários de maior poder aquisitivo que são beneficiados, também, por uma maior qualidade na atenção à saúde. Evidencia-se, ainda, que entre os portadores de doenças crônicas, os usuários com um maior poder aquisitivo detêm um percentual mais elevado de acompanhamento médico, além de realizarem com maior frequência os exames periódicos $\left.{ }^{(19)},{ }^{(20)},{ }^{(21)}\right)$. Quanto à cobertura hospitalar pelo SUS, encontraram uma menor taxa de utilização na região Sudeste (Nunes et al). Assim, a região que detém um melhor nível socioeconômico possui um menor índice de internação, o que pode estar associado à qualidade da atenção básica ou à internação pelo âmbito privado.

O contexto assinalado acima, segundo Neri e Soares ${ }^{(22)}$, viabiliza relações entre as desigualdades de saúde e as iniquidades sociais. De acordo com Travassos et $a^{(23)}$, ainda se convive com vários fatores que influenciam o padrão de consumo das ações e serviços de saúde no Brasil. Esses reproduzem um acúmulo de desigualdades e distanciam o SUS dos princípios que o regem. Uma das estratégias de enfrentamento para esse quadro é a tentativa de priorização da atenção básica, buscando reverter o modelo assistencial "hospitalocêntrico".

Cabe, assim, ao Poder Executivo fortalecer as quatro vertentes do SUS e viabilizar processos de negociação entre os três poderes, em uma relação de reciprocidade privilegiando o que Putnam $^{(24)}$ classifica de articulações horizontais, capazes de "sustentarem a coesão comunitária e a ação coletiva" e, por isso, favorecem a sustentação de uma política de Estado e uma maior efetividade na resolução dos dilemas de ação coletiva. A coparticipação ou a cogestão parece ser um das soluções para se atingir o Estado de Direito Social. Os critérios técnicos precisam ser observados para garantir maior efetividade à política de saúde e maior eficiência do gasto. Cabe ao controle social averiguar a observação aos princípios do SUS e se as escolhas estão

(19) NUNES, Augusto et al. Medindo as desigualdades em saúde no Brasil: uma proposta de monitoramento. Brasília: Organização Pan-Americana de Saúde, Instituto de Pesquisa Econômica Aplicada, 2001. 224 p.

(20) REIS, Carlos Octávio Ocké. Desigualdades no acesso aos serviços de saúde. In: NEGRI, Barjas; DI GIOVANNI, Geraldo (Org.). Brasil: radiografia da saúde. Campinas: UNICAMP, 2001. p. 579-585.

(21) PUCCINI, Rosana Fiorini et al. Equidade na atenção pré-natal e ao parto em área da Região Metropolitana de São Paulo, 1996. Cadernos de Saúde Pública, Rio de Janeiro, v. 19, n. 1, p. 35-45, 2003.

(22) NERI, Marcelo; SOARES, Wagner. Desigualdade social e saúde no Brasil. Caderno de Saúde Pública, Rio de Janeiro, v. 18 supl., p. 77-87, 2002.

(23) TRAVASSOS, Cláudia et al. Desigualdades geográficas e sociais na utilização de serviços de saúde no Brasil. Ciência \& Saúde Coletiva, Rio de Janeiro, v. 5, n. 1, p. 133-149, 2000.

(24) PUTNAM, Robert. Comunidade e democracia: a experiência da Itália moderna. Rio de Janeiro: FGV, 1996. 260 p. 
maximizando o resultado em termos de acesso às ações e serviços de saúde e melhora das condições de saúde da população(25).

Almeida(26) enfatiza que o aperfeiçoamento dos serviços públicos, mediante a regulamentação e emancipação, é um ideal a ser alcançado para que o Poder Judiciário não se transforme em mais uma porta de entrada no sistema. Dessa maneira, ele ocupa a lacuna deixada pelo Executivo e Legislativo. Para evitar a existência desses espaços, várias estratégias podem ser adotadas, que vão desde uma maior qualificação dos gestores para adequar o SUS às demandas e necessidades de seus usuários; a participação do Poder Legislativo com leis específicas e regulamentadoras na área social, saúde e ambiente que possam fortalecer os propósitos do sistema. A aprovação da Emenda Constitucional n. 29 (EC n. 29) seria uma delas. Além de interlocuções efetivas entre os três poderes que resultem na consolidação dos interesses coletivos no campo da saúde, uma vez que quando falta ao Judiciário a contextualização dos fatos, ele se torna rígido seguidor da carta mãe. Essencialmente, quando ele se defronta com uma participação social frágil ou uma política vulnerável a questionamentos, a organização jurídica local torna-se um elemento fundamental para consolidação do direito à saúde, assumindo a posição de determinantes no cuidado à saúde(27).

\section{Possíveis implicações das ações de judicialização}

Evidenciou-se neste estudo um número acentuado de decisões judiciais que se ampararam apenas na CF/88, sem levar em consideração as políticas públicas. Sendo que a regulamentação do SUS, como um sistema público de saúde universal, demandou um conjunto de políticas articuladas. Elas abrangem estrutura, processos e resultados do SUS, de maneira a resguardar ao usuário e à União, Estados e Municípios a qualidade dos serviços profissionais e institucionais, bem como, preservar o uso adequado do dinheiro público.

Pondera-se, ainda, que, dentre as políticas públicas existentes no Brasil, as referentes à saúde merecem destaque, uma vez que não se esgotaram com a regulamentação do SUS, além de se caracterizarem como política de Estado, comprometidas com a universalização de suas ações e voltadas às necessidades do coletivo, evitam privilegiar interesses individuais ou de

(25) VIEIRA, Fabíola Sulpino. op. cit., p. 365-369.

(26) ALMEIDA, Gregório Assagra. Público e o privado na saúde. Anotações feita em aula: Curso de Direito Sanitário, Escola de Saúde Pública de Minas Gerais. Módulo fevereiro-2008. Belo Horizonte, fev. 2008. p. 2.

(27) DALLARI. Sueli Gandolfi. Direito e saúde. Balanço da Saúde no Brasil: SUS, participação social, formação sanitária e agências reguladoras. Brasília, n. 13, p. 12-13, maio 2007. 
grupos específicos. Situação que parece estar favorecida, a partir da judicialização da saúde, pois, de acordo com Vieira ${ }^{(28)}$, corre-se o risco de privilegiar os usuários que têm maior poder aquisitivo para pagar advogados ou maior acesso à informação. Este fato, de certa maneira, pode gerar uma exclusão dos sujeitos de menor poder socioeconômico e, provavelmente, com maiores necessidades em saúde, sobretudo, diante da estrutura social e política vigente no Brasil, caracteristicamente dual, uma descrita pelos cientistas políticos, economistas, jornalistas e políticos, que o valorizam como nação, com características de contemporaneidade, aberta às mudanças e ao progresso. A outra descrita pelos cientistas sociais, como uma "sociedade" atrasada e rústica, que privilegia algumas formas de particularismos e se distancia de uma típica sociedade moderna, principalmente, quando diversos autores como Da Matta ${ }^{(29)(30)}$, Reis ${ }^{(31)}$, Heringer ${ }^{(32)}$, Nunes ${ }^{(33)}$, Vaitsman $^{(34)}$, vêm trabalhando as tradicionais formas de particularismos existentes no Brasil e suas repercussões sociológicas. Entende-se por particularismo uma doutrina que se apoia na desigualdade de direitos e obrigações entre os vários cidadãos ou grupo desses, na qual os interesses pessoais ou de determinados grupos sobrepujam o interesse coletivo. Situação próxima às consequências originadas a partir de algumas ações judiciais que envolvem o SUS. Pois, o judiciário pode, então, estar sendo usado por meio de estratégias como o "jeitinho brasileiro" na tentativa de adequar as leis universais aos interesses individuais ou de alguns poucos, independente das suas reais necessidades.

Nesta perspectiva, o Judiciário pode estar contaminando a concepção de sistema social e a própria dinâmica de uma possível transformação social, ao se situar como uma estratégia de direcionar, regular ou facilitar o atendimento e/ou acesso às ações de serviço de saúde. O estímulo a essa utilização tem sido associado, na visão de alguns integrantes do campo da saúde, ao apelo do uso de artefatos de alta tecnologia disponíveis no campo da saúde. Esses são trabalhados caprichosamente pelos meios de comunicação de massa, que reproduz a noção de um mercado de quanto maior o custo, maior a efetividade.

(28) VIEIRA, Fabíola Sulpino. op. cit., p. 365-369.

(29) DAMATTA, Roberto. A casa \& a rua: espaço, cidadania, mulher e morte no Brasil. 4. ed. Rio de Janeiro: Guanabara, 1987. 181 p.

(30) Id. O que faz do Brasil, Brasil? Rio de Janeiro: Ed. Rocco, 1994. 126 p.

(31) REIS, Elisa. Percepções da elite sobre pobreza e desigualdade. Revista Brasileira de Ciências Sociais, São Paulo, v. 15, n. 42, p. 143-152, 2000.

(32) HERINGER, Rosana. Desigualdades raciais no Brasil: síntese de indicadores e desafios no campo das políticas públicas. Caderno de Saúde Pública, Rio de Janeiro, v. 18 supl., p. 57-65, 2002. (33) NUNES, Edson de Oliveira. A gramática política do Brasil. Brasília: Jorge Zahar, 2003. 146 p. (34) VAITSMAN, Jeni. Desigualdades sociais e duas formas de particularismo na sociedade brasileira. Caderno de Saúde Pública, Rio de Janeiro, v. 18 supl., p. 37-46, 2002. 
Cabe, ainda, destacar o lugar que a mídia ocupa na dinâmica dos processos sociais ao socializar concepções harmoniosas em que predominam certos ideais de saúde. Realçam-se os largos benefícios destas produções tecnológicas, promovendo uma indução ao consumo de tecnologias "ditas" de ponta, com um poder de resolução proporcional a sua inacessibilidade. Nessa circunstância, surge uma intensa necessidade de utilização destes bens e um ilusório poder de consumo. O que se verifica é que a centralização do poder na tecnologia, nos medicamentos e nos profissionais da saúde tem despertado no público uma medicalização sem limites ${ }^{(35)},{ }^{(36)},{ }^{(37)},{ }^{(38)}$. Situação que pode estar levando os usuários à procura do Judiciário para o acesso a essa tecnologia que, em algumas situações, defere a ação, negligenciando os preceitos éticos e científicos que também dão sustentação à política de saúde vigente.

A assistência terapêutica integral deve ser garantida a toda pessoa que busca diagnóstico e tratamento nos serviços de saúde do SUS, de acordo com suas normas técnicas, administrativas, seus princípios e diretrizes. Santos $^{(39)}$ afirma que a incorporação das tecnologias na saúde pública deve ser pautada pelo necessário, oportuno, razoável, conveniente e essencial para a garantia da saúde coletiva e individual e não porque existem no mercado. Esse, geralmente, compreende a saúde em uma concepção biologicista, como um bem de consumo e negligencia o caráter histórico-social do processo saúde-doença na coletividade, demarcado por diversos autores como Laurel/(40), Rouquayro/(41) e Minayo(42). Dessa maneira,

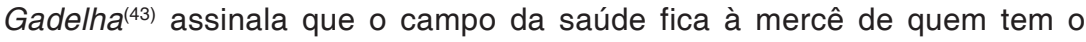
produto de maior poder tecnológico, muitas vezes, associado ao domínio do capital e ao lucro. E, diante de um usuário, antes cidadão, agora consumidor, o SUS vê os seus princípios fragilizados a partir das decisões judiciais que

(35) CAPRA, Fritjof. O ponto de mutação. São Paulo: Cultrix, 1982. 447 p.

(36) GUARESCHI, Pedrinho Arcides et al. Textos em representações sociais. 2. ed. Petrópolis: Vozes, 1995. $324 \mathrm{p}$.

(37) SANTOS, Boaventura de Souza. Pela mão de Alice: o social e o politico na pós-modernidade. 5. ed. São Paulo: Cortez, 1999. 348 p.

(38) MELO, Marilene Barros de. Saúde coletiva e mestrado em Odontologia: um estudo de representação social. 2002. Dissertação (Mestrado) - Faculdade de Odontologia, Universidade Federal de Minas Gerais, Minas Gerais, 2002.

(39) SANTOS, Boaventura de Souza. A crítica da razão indolente: contra o desperdício da experiência. 2. ed. São Paulo: Cortez, 2000. 415 p.

(40) LAURELL, Asa Cristina. A saúde-doença como processo social. In: NUNES, Everardo Duarte (Org.). Medicina social: aspectos históricos e teóricos. São Paulo: Global Editora, 1983. p. 133-158. (41) ROUQUAYROL, Maria Zélia. Epidemiologia, história natural e prevenção de doenças. In: Epidemiologia \& Saúde. 4. ed. Rio de Janeiro: MEDSI, 1994. p. 7-22.

(42) MINAYO, Maria Cecília de Souza. O desafio do conhecimento: pesquisa qualitativa em saúde. 4. ed. São Paulo: Hucitec,1996. 269 p.

(43) GADELHA, Carlos Augusto Grabois. Desenvolvimento, complexo industrial da saúde e política industrial. Revista de Saúde Pública, São Paulo, v. 40 supl., p. 11-23, 2006. Scielo Brasil. Disponível em: <http://www.scielo.br/scielo.php?pid=S0034-89102006000400003\&script=sci_arttext>. Acesso em: 20 dez. 2008. 
podem favorecer a iniquidade social. Salienta-se que a manutenção ou o aprofundamento deste tipo de exclusão social tem-se a persistência do atual sistema de saúde segmentado, seletivo no acesso aos serviços segundo padrões de mercado.

O Judiciário ao entender a saúde como direito e não considerar as políticas públicas pode estar aproximando apenas do seu aspecto biologicista ou reproduzindo a seletividade do mercado imposta ao usuário. uma vez que as políticas e programas sociais têm um compromisso com o contexto sócio-histórico-cultural, e por isso, tem característica distributiva e de amplitude de acesso. Quando se observa a partir do SPDISA que o direito alcançado pela decisão judicial tem uma relação próxima com medicamentos de última geração, pondera-se sobre a disponibilização a um usuário de um valor financeiro que poderia ser destinado a ações promotoras de saúde a um maior número de usuários, visto que, de acordo com Dallari(44). cada $R \$ 1$ gasto em saneamento equivale a $\mathrm{R} \$ 1.000$ em gasto com medicamentos. Starfield ${ }^{(45)}$ alerta que os recursos investidos no cuidado às enfermidades poderiam ser empregados na atenção básica, principalmente para aqueles que não podem pagar por eles.

$\mathrm{E}$, na visão de Barroso $^{(46)}$, o Judiciário ao não dominar as questões que envolvem as políticas de saúde, ao deferir as ações judiciais referentes ao SUS, pode beneficiar usuários que apresentam demandas e não necessidades reais, já que o acesso ao Poder Judiciário independe da estratificação social. O autor argumenta que o Juiz é um ator social de casos concretos no âmbito da microjustiça e a Administração Pública da macrojustiça.

É importante considerar também que a garantia à saúde está além do acesso universal, passando por políticas que possibilitem aos indivíduos a moradia adequada, saneamento básico, emprego, renda, lazer e educação. A universalidade, integralidade, igualdade e equidade no acesso aos serviços de saúde ficam comprometidas por causa do fato de estarem vinculadas a recursos limitados. Isso leva à recorrência de uma regulação mediante políticas públicas.

Cabe, então, ao Poder Judiciário reconhecer que o direito à saúde passa pelas políticas sociais e econômicas exigindo políticas públicas abrangentes, além de ações intersetoriais e transdisciplinares, pois a saúde perpassa a sociedade como um todo. Nesta perspectiva, estará assumindo a posição de um ator extremamente poderoso para colaborar na adequação dessas políticas e na organização do acesso às ações e serviços de saúde.

(44) DALLARI, Sueli Gandolfi. op. cit., p.12-13.

(45) STARFIELD, Barbara. Atenção primária: equilíbrio entre necessidades de saúde, serviços e tecnologia. Brasília: UNESCO, 2002. 725 p.

(46) BARROSO, Luís Roberto. Semana do Ministério Público da Procuradoria-Geral de Justiça do Estado de Minas Gerais. 20 anos da Constituição Federal de 1988 pela ótica do neoconstitucionalismo. 2008. 


\section{CONSIDERAÇÕES FINAIS}

A partir da análise que este estudo realizou do SPDISA, observa-se um aumento do número de decisões judiciais que aborda as ações e serviços de saúde referentes ao SUS e que a base legal da decisão judicial tem sido parte do art. 196, uma vez que, o Judiciário não tem considerado as políticas sociais e econômicas que procuram contemplar as disparidades locais e regionais, direcionando essas ações e serviços no sentido de garantir o direito à saúde. Situações que tem promovido uma divisão entre os três poderes e delegado uma grande responsabilidade na participação do Poder Judiciário neste campo.

Diante disso, alguns questionamentos têm surgido; um deles este estudo buscou responder. Entretanto, outros ainda necessitam ser trabalhados, entre eles, o limite cabível para que os Poderes Judiciário e Legislativo se apresentem dentro da discricionalidade do Poder Executivo. bem como, os limites administrativos e responsabilidades do Executivo. configurando um espaço profícuo para a pesquisa no campo do direito sanitário. Essencialmente, quando se evidencia um aumento de cerca de $80 \%$ das ações judiciais em saúde, a partir de 2003, reflexo de muitas variáveis que merecem ser estudadas pois trazem consigo comprometimentos importantes, visto que, o sujeito ao buscar proteção para se tornar foco nas ações de saúde e dessa forma garantir o seu direito à saúde no judiciário termina por comprometer a abrangência da coletividade. Tem-se um espectro de ações voltadas para uma qualidade em saúde ampliado, mas centrado em um ou em determinados grupos, em detrimento de muitos.

O art. 196 ao enfatizar a saúde como direito de todos vem sustentar o previsto na Declaração Universal de Direitos Humanos, bem como no Pacto Internacional dos Direitos Econômicos, Sociais e Culturais, como uma das condições indispensáveis para a promoção da dignidade e ao livre desenvolvimento humano. Sob a ótica do Direito Constitucional, reconhece-se que a implementação do direito à saúde, positivado no art. 6으 da Constituição Brasileira, demanda uma atividade estatal. Essa implica no fornecimento de bens materiais e, por isso, dependente dos recursos orçamentários e da organização e articulação entre os três poderes e a sociedade no sentido de viabilizar esse direito.

Faz-se necessário, então, considerar o impacto que as decisões judiciais podem promover no âmbito da gestão em saúde e na coletividade, a partir de uma noção do contexto geral, o que demanda uma estância onde as questões referentes à saúde assumam uma condição de transversalidade entre os três poderes que conflua para atender as demandas de saúde, e, ações que envolvem um maior vínculo com a coletividade, mais complexas, articuladas e efetivas, mediante políticas de médio e longo prazo, 
caracterizando-se como uma Política de Estado. Cabe lembrar que dentre as políticas públicas, as referentes à saúde vêm se consolidando a partir de reformulações em prol da resolução dos dilemas de ação coletiva, sustentando-as em alicerces públicos e tornando-as menos susceptíveis aos particularismos vigentes na sociedade brasileira.

No entanto, em virtude de seu breve percurso histórico, o SUS ainda se encontra em fase de estruturação e consolidação e, que apesar do seu compromisso público de responsabilização quanto ao seu mundo social, encontra-se vulnerável às incursões que visam fragilizá-lo ou fortalecê-lo. Por isso, demanda a construção de bases sólidas que integrem novas modalidades de gestão que consigam abranger a relação sujeito/coletividade/ações, serviços de saúde e os três poderes responsáveis pela organização do estado. Além de transcender os particularismos, as políticas de governo de curto prazo e o padrão de compromissos com os interesses do capital. visando uma discussão política mais ampla que favoreça uma oferta satisfatória de serviços de saúde e uma aplicação adequada dos recursos voltados a essa área.

\section{REFERÊNCIAS BIBLIOGRÁFICAS}

ALMEIDA, Célia Maria. Reforma de sistemas de servicios de salud y equidad en América Latina y el Caribe: algunas lecciones de los años 80 y 90 . Caderno de Saúde Pública, Rio de Janeiro, v. 18, n. 4, p. 905-925, 2002.

ALMEIDA, Gregório Assagra. Público e o privado na saúde. Anotações feitas em aula: Curso de Direito Sanitário, Escola de Saúde Pública de Minas Gerais. Módulo fevereiro-2008. Belo Horizonte, fev. 2008.

ARENDT, Hannah. O que é política? Trad. Reinaldo Guarany. 6. ed. Rio de Janeiro: Bertrand Brasil, 2006.

BARDIN, Laurence. Análise de conteúdo. Lisboa: Edições 70, 1977. 287 p.

BARROSO, Luís Roberto. Da falta de efetividade a judicialização excessiva: direito à saúde, fornecimento gratuito de medicamentos e parâmetros para a atuação judicial. Revista Jurídica UNIJUS, Minas Gerais, v. 15, p. 13-38, 2008.

Semana do Ministério Público da Procuradoria-Geral de Justiça do Estado de Minas Gerais. 20 anos da Constituição Federal de 1988 pela ótica do neoconstitucionalismo. 2008.

BRASIL. Ministério da Saúde. Lei n. 8.080, de 19 de setembro de 1990. Dispõe sobre as condições para promoção, proteção e recuperação da saúde, a organização e funcionamento dos serviços correspondentes e dá outras providências. Diário Oficial da União, Brasília, 20 set. 1990. 
Ministério da Saúde. Lei n. 8.142, de 28 de dezembro de 1990. Dispõe sobre a participação da comunidade na gestão do Sistema Único de Saúde - SUS e sobre as transferências intergovernamentais de recursos financeiros na área da saúde e dá outras providências. Diário Oficial da União, Brasília, 28 dez. 1990. Disponível em: <http://www81.dataprev.gov.br/ sislex/paginas/42/1990/8142.htm>. Acesso em: 18 dez. 2008.

Presidência da República. Constituição da República Federativa do Brasil. Brasília: Senado Federal, 1988. Disponível em: <http:// www.planalto.gov.br/ccivil_03/Constituicao.htm>. Acesso em: 15 dez. 2008.

BUCCI, Maria Paula Dallari. Cidadania, direitos humanos e políticas públicas: perspectivas de justiça no Século XXI. Cadernos de Direito e Cidadania III, São Paulo, 2002.

CAPRA, Fritjof. O ponto de mutação. São Paulo: Cultrix, 1982. 447 p.

CARVALHO, José Murilo. Pontos e bordados. Belo Horizonte: Ed. UFMG, 1999. $457 \mathrm{p}$.

DALLARI, Sueli Gandolfi. Direito e saúde. Balanço da Saúde no Brasil: SUS, participação social, formação sanitária e agências reguladoras. Brasília, n. 13, p. 12-13, maio 2007.

DAMATTA, Roberto. A casa \& a rua: espaço, cidadania, mulher e morte no Brasil. 4. ed. Rio de Janeiro: Guanabara, 1987. 181 p.

O que faz do Brasil, Brasil? Rio de Janeiro: Ed. Rocco, 1994. 126 p.

ELIAS, Paulo Eduardo. Estado e saúde: os desafios do Brasil contemporâneo. Revista São Paulo Perspectiva, São Paulo, v. 18, n. 3, p. 41-46. 2004.

GADELHA, Carlos Augusto Grabois. Desenvolvimento, complexo industrial da saúde e política industrial. Revista de Saúde Pública, São Paulo, v. 40 supl., p. 11-23, 2006. Scielo Brasil. Disponível em: <http://www.scielo.br/ scielo.php?pid=S0034-89102006000400003\&script=sci_arttext>. Acesso em: 20 dez. 2008.

GUARESCHI, Pedrinho Arcides et al. Textos em representações sociais. 2. ed. Petrópolis: Vozes, 1995. 324 p.

HERINGER, Rosana. Desigualdades raciais no Brasil: síntese de indicadores e desafios no campo das políticas públicas. Caderno de Saúde Pública, Rio de Janeiro, v. 18 supl., p. 57-65, 2002.

LAURELL, Asa Cristina. A saúde-doença como processo social. In: NUNES, Everardo Duarte (Org.). Medicina social: aspectos históricos e teóricos. São Paulo: Global Editora, 1983. p. 133-158.

LUCCHESE, Patrícia Tavares Ribeiro. Equidade na gestão descentralizada do SUS: desafios para a redução de desigualdades em saúde. Ciência \& Saúde Coletiva, Rio de Janeiro, v. 8, n. 2, p. 439-448, 2003. 
MELO, Marilene Barros de. Saúde coletiva e mestrado em Odontologia: um estudo de representação social. 2002. Dissertação (Mestrado) — Faculdade de Odontologia, Universidade Federal de Minas Gerais, Minas Gerais, 2002.

MELO, Maurício de Medeiros. O direito coletivo prestacional à saúde e o poder judiciário: a concretização do art. 196 da Constituição de 1988 pela via jurisdicional. 2007. Dissertação (Mestrado) - Faculdade de Direito, Universidade Federal do Rio Grande do Norte, Natal. 2007. Disponível em: <http://bdtd.bczm.ufrn.br/tedesimplificado//tde_busca/ arquivo.php?codArquivo=1162>. Acesso em: 03 dez. 2008.

MINAYO, Maria Cecília de Souza. O desafio do conhecimento: pesquisa qualitativa em saúde. 4. ed. São Paulo: Hucitec,1996. 269 p.

NERI, Marcelo; SOARES, Wagner. Desigualdade social e saúde no Brasil. Caderno de Saúde Pública, Rio de Janeiro, v. 18 supl., p. 77-87, 2002.

NUNES, Augusto et al. Medindo as desigualdades em saúde no Brasil: uma proposta de monitoramento. Brasília: Organização Pan-Americana de Saúde, Instituto de Pesquisa Econômica Aplicada, 2001. 224 p.

NUNES, Edson de Oliveira. A gramática política do Brasil. Brasília: Jorge Zahar, 2003. $146 \mathrm{p}$.

OPS - ORGANIZACIÓN PANAMERICANA DE LA SALUD. La cooperación de la Organización Panamericana de la Salud ante los procesos de reforma del sector salud. Washington, 1997. $31 \mathrm{p}$.

PAIM, Jairnilson Silva. Políticas de saúde no Brasil. In: ROUQUAYROL, Maria Zélia; ALMEIDA FILHO, Naomar; TAMBELLINI, Anamaria Testa (Orgs.) et al. Epidemiologia \& Saúde. 6. ed. Rio de Janeiro: Medsi, 2003. p. 587-603.

PUCCINI, Rosana Fiorini et al. Equidade na atenção pré-natal e ao parto em área da Região Metropolitana de São Paulo, 1996. Cadernos de Saúde Pública, Rio de Janeiro, v. 19, n. 1, p. 35-45, 2003.

PUTNAM, Robert. Comunidade e democracia: a experiência da Itália moderna. Rio de Janeiro: FGV, 1996. 260 p.

REIS, Carlos Octávio Ocké. Desigualdades no acesso aos serviços de saúde. In: NEGRI, Barjas; DI GIOVANNI, Geraldo (Org.). Brasil: radiografia da saúde. Campinas: UNICAMP, 2001. p. 579-585.

REIS, Elisa. Percepções da elite sobre pobreza e desigualdade. Revista Brasileira de Ciências Sociais, São Paulo, v. 15, n. 42, p. 143-152, 2000.

ROUQUAYROL, Maria Zélia. Epidemiologia, história natural e prevenção de doenças. In: Epidemiologia \& Saúde. 4. ed. Rio de Janeiro: MEDSI, 1994. p. 7-22.

SANTOS, Boaventura de Souza. A crítica da razão indolente: contra o desperdício da experiência. 2. ed. São Paulo: Cortez, 2000. 415 p. 
Pela mão de Alice: o social e o politico na pós-modernidade. 5. ed. São Paulo: Cortez, 1999. 348 p.

SOARES, Orlando. Comentários à Constituição da República Federativa do Brasil: (promulgada em 05.10.1988). 10. ed. Rio de Janeiro: Forense, 1999. $903 \mathrm{p}$.

STARFIELD, Barbara. Atenção primária: equilíbrio entre necessidades de saúde, serviços e tecnologia. Brasília: UNESCO, 2002. 725 p.

TRAVASSOS, Cláudia et al. Desigualdades geográficas e sociais na utilização de serviços de saúde no Brasil. Ciência \& Saúde Coletiva, Rio de Janeiro, v. 5, n. 1, p. 133-149, 2000.

VAITSMAN, Jeni. Desigualdades sociais e duas formas de particularismo na sociedade brasileira. Caderno de Saúde Pública, Rio de Janeiro, v. 18 supl., p. 37-46, 2002.

VALLINDER, Torbjorn. When the Courts Go Marching In. In: VALLINDER, Torbjorn; TATE, Neal. The global expansion of judicial power: the judicialization of politics. New York: New York University Press, 1995.

VIEIRA, Fabíola Sulpino. Ações judiciais e direito à saúde: reflexão sobre a observância aos princípios do SUS. Revista de Saúde Pública, São Paulo, v. 42, p. 365-369, 2008. 